Gut, 1982, 23, 1037-1043

\title{
Bacterial and fungal infection in children with fulminant hepatic failure: possible role of opsonisation and complement deficiency
}

\author{
V F LARCHER, * R J WYKE, A P MOWAT, and R WILLIAMS \\ From the Department of Child Health and the Liver Unit, King's College Hospital and Medical School, \\ London
}

SUMMARY Serious bacterial infection, including eight episodes of bacteraemia, developed in seven of $15(47 \%)$ children with fulminant hepatic failure. Those with infections had a slightly higher leucocyte response than those who did not. Serum immunoglobulin concentrations were normal or raised in all patients. Opsonisation of heat-killed baker's yeast, functionally measured total haemolytic complement, C4, C5, total alternative pathway activity, factor B and D activity, and $C 3$ concentrations were all significantly $(p<0.005)$ reduced at presentation but returned to normal in those who survived. The severity of defects in yeast opsonisation, C4, and factor B activity at presentation were significantly correlated with the subsequent development of infection. In five patients bacteraemia occurred at a time when opsonisation and complement components were defective. Plasma infusions in vivo improved opsonisation in vitro and only one bacterial isolate was obtained within four days of such an infusion. Those patients who developed infection had received significantly $(\mathrm{p}<0.05)$ fewer plasma infusions than those who did not. Our findings suggest that both alternative and classical pathways of complement are defective in children with severe liver disease and may contribute to the susceptibility of such patients to infections. Plasma infusions might be useful in reducing the incidence of bacterial infection in such conditions.

Bacterial infection is a major cause of mortality and morbidity among children with fulminant hepatic failure ${ }^{1}$ although the reasons for their increased susceptibility to infection are little understood. Of possible importance are changes in serum complement; this is a major factor in host defence ${ }^{2}$ as it is required, either alone or with immunoglobulin, to coat (opsonise) bacteria before phagocytosis by polymorphonuclear leucocytes. Defects in complement components of both classical ${ }^{34}$ and alternative ${ }^{5} 6$ pathways are associated with an increased incidence of infection. Opsonisation of heat-killed baker's yeast is apparently dependent on the integrity of the alternative pathway of complement ${ }^{7}$ and a primary defect in yeast opsonisation is also associated with an increased incidence of infection. ${ }^{8}$ Secondary defects of yeast opsonisation have been reported in children with

\footnotetext{
* Address for correspondence: Dr V F Larcher, Department of Child Health, King's College Medical School, London SE5 8RX.

Received for publication 6 March 1982
}

severe liver disease. ${ }^{9}$

We therefore examined the relationship between infection and yeast opsonisation and complement deficiencies in children with fulminant hepatic failure.

\section{Methods}

Fifteen children, mean age 5.4 years (range 0.3-13 years), were studied: all fulfilled criteria for diagnosis of fulminant hepatic failure ${ }^{10}$ and were in grade III-IV encephalopathy ${ }^{11}$ when initially studied. Four had IgM antibodies to hepatitis A but none had hepatitis B surface antigen or antibody; the cause of the hepatic necrosis was not established in the other 11 patients. All patients received standard supportive treatment including intravenous dextrose, cimetidine, vitamin supplements, oral lactulose and neomycin, and magnesium sulphate enemata. ${ }^{11}$ In addition, all received a variable number of infusions of fresh frozen plasma at a dose 
of $10-20 \mathrm{ml} / \mathrm{kg}$ to replace defective clotting factors. Nine received temporary liver support by haemodialysis using a polyacrylonitrile membrane for periods ranging from two to four hours on one to five occasions. Two patients in whom renal failure developed terminally received peritoneal dialysis for the last 24 hours of life.

Regular routine bacterial surveillance of patients was maintained by means of cultures for bacteria and fungi made from swabs taken from throat, nose, and surgical wounds and from specimens of stool, urine, and blood. Specimens were obtained daily during the period of grade III-IV encephalopathy, thence weekly or more frequently when clinically indicated. Blood cultures were obtained from peripheral veins after swabbing the skin thoroughly with isopropyl alcohol. The material obtained was innoculated into standard broth cultures which included penicillinase. Pure growth of an organism from two bottles was considered necessary for the diagnosis of bacteraemia.

For opsonisation and complement assays venous blood was obtained on admission at the stage of grade III-IV encephalopathy and allowed to clot at room temperature; serum was separated within two hours and stored in aliquots at $-70^{\circ} \mathrm{C}$. Serial samples were obtained in 10 patients (eight fatal cases, two survivors), five of whom developed infection. In nine cases specimens were obtained after clearance of encephalopathy. Sera were also obtained from six survivors after discharge from hospital; in two within two months of recovery and in four others, not studied in the acute phase of their illness, over 12 months after recovery. Control samples were taken from 26 age-matched children admitted for routine surgical procedures who had no evidence of liver disease, infection, or allergy and in whom venepuncture was necessary as part of their management.

\section{YEAST OPSONISATION}

Opsonisation of heat-killed baker's yeast was measured by a Coulter counter method ${ }^{12}$ and results were expressed as percentage of yeasts phagocytosed by normal polymorphonuclear leucocytes in the presence of $5 \%$ serum after incubation at $37^{\circ} \mathrm{C}$ for 30 minutes. The concentration of serum and the calculated innoculum of yeast particles per cell had previously been shown to provide optimal opsonisation of yeasts for phagocytosis. ${ }^{12}$ In each batch sera from age-matched normal children and children with a primary defect in yeast opsonisation were included as controls.

COMPLEMENT COMPONENTS

Total haemolytic complement (CH50), C4, C5 total alternative pathway activity and factors B and D were measured functionally by radial haemolytic diffusion in agarose. ${ }^{13} 14 \mathrm{C} 3$ concentration was measured antigenically by radial immunodiffusion against rabbit antisera. Results were expressed as the percentage of activity of a control serum pool.

The significance of the difference in percentage yeasts phagocytosed and complement activity in sera from patients and controls was assessed by Student's $t$ test. Data from patients with and without infection were compared by Willcoxon's rank sum test.

\section{Results}

INCIDENCE AND TYPE OF INFECTION

Seven $(47 \%)$ of 15 children with fulminant hepatic failure had infective episodes characterised by positive bacterial or fungal cultures during the course of their illness (Table 1). They did not differ from others with respect to age, sex, severity of initial disturbance of liver function tests, period in grade IV encephalopathy, or in length of hospital stay. The occurrence of renal failure, gastrointestinal haemorrhage, and use and duration of temporary liver support was similar in the two groups.

Six patients had eight positive blood cultures (one had three distinct episodes with separate organisms) four to 37 days (mean 12) after onset of encephalopathy, but only two episodes occurred (cases 1 and 2) when the patients were still encephalopathic. The organisms isolated were $S$. aureus on three occasions, $S$. pneumoniae on two, and $S$. viridans, $E$. coli, and C. albicans on one occasion each. In four patients bacteraemia occurred within five days of death. All patients who died had continuing evidence of severe liver disease with profoundly abnormal liver function tests, clotting studies, and post mortem liver biopsy.

\section{POSSIBLE SOURCES OF INFECTION}

In one patient (case 3 ) $E$. coli was isolated from the urine two days before isolation of an organism having identical antibiotic sensitivities from blood culture. Additionally, urinary tract infection with bacteruria and pyuria occurred in four patients, three of whom had undergone urinary catheterisation, while one had chronic pyelonephritis at necropsy. In three patients infection at the site of arteriovenous shunt insertion occurred from which $S$. aureus were cultured, in two cases within two days of discovery of bacteraemia. In another child (case 6) $S$. aureus was isolated from a generalised impetiginous rash two days before its detection in a blood culture. One patient (case 2) had clinical and radiological features of lobar 


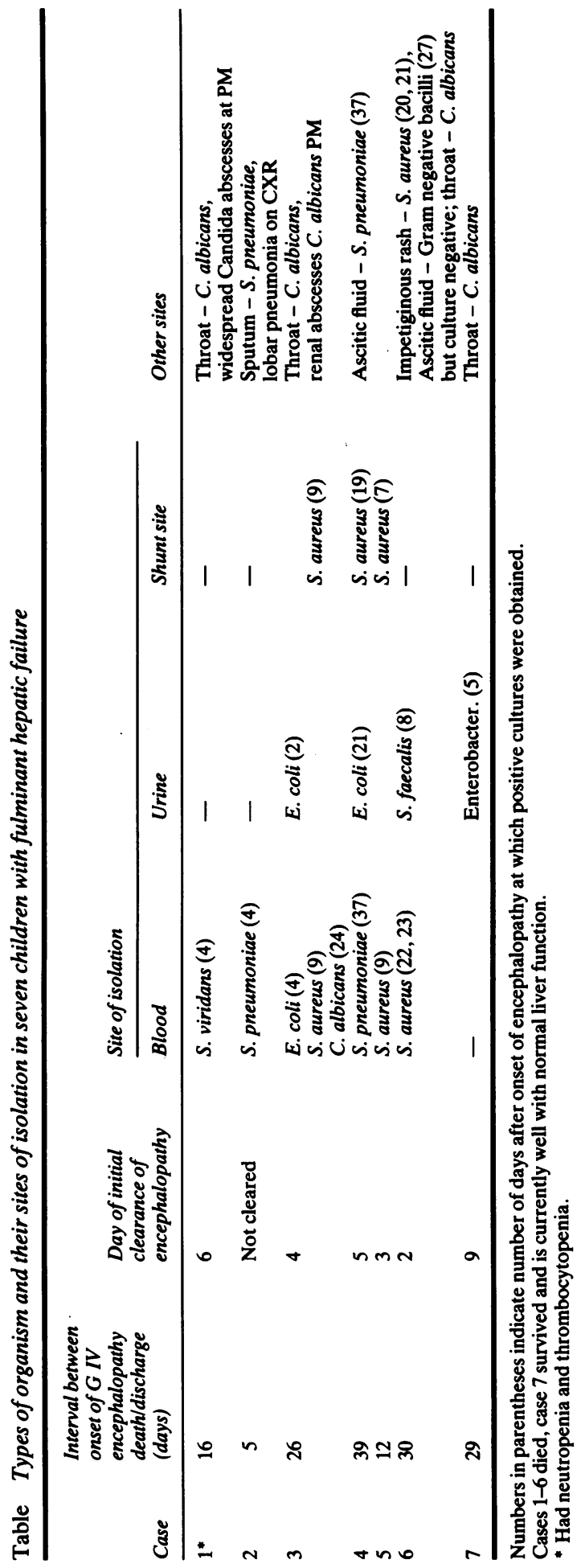


pneumonia with $S$. pneumoniae isolated from sputum and blood. $C$. albicans was isolated from the oropharynx in four patients (cases 1,3,6, and 7) and from blood culture in one (case 3 ). All had received or were receiving broad spectrum antibiotics. In cases 1 and 3, candida renal abscesses were present at necropsy.

\section{HOST RESPONSES TO INFECTION}

The highest leucocyte count seen in six patients who developed bacteraemia ranged from $4.4-39.8 \times 10^{9} / 1$ (mean $22.2 \times 10^{9} / 1$ ) either shortly before or on the day of detection of bacteraemia. The highest leucocyte count in eight children with negative cultures was lower, ranging from $11.2-18.7 \times 10^{9} / 1$ (mean $14.3 \times 10^{9} / 1$ ) but not significantly so. One patient who developed bacteraemia (case 1) had severe neutropenia $\left(<0.5 \times 10^{9} / 1\right)$ requiring white cell infusions. Lymphocyte counts were normal in all patients studied. Pyrexia (axillary temperature $>38^{\circ} \mathrm{C}$ ) occurred in three patients with infections and three without. Serum immunoglobulin levels were normal for age in 10 patients, but concentrations of one or more subclass were raised in five.

\section{DEFECTS IN YEAST OPSONISATION AND \\ COMPLEMENT}

Sera from all patients in grade III-IV encephalopathy had defective opsonising capacity, with a mean percentage of yeast phagocytosed (19 SD $5.6 \%$ ) significantly less than the mean for controls (52 SD $10 \% \mathrm{p}<0.005$ ). Functional activity of factors of both classical and alternative pathways of complement measured simultaneously were significantly $(\mathrm{p}<0.005)$ reduced to a mean of less than $45 \%$ of control (Fig. 1). Opsonisation of yeasts, functional activities of factors $\mathrm{B}$ and $\mathrm{C} 4$ were significantly lower $(p<0.05)$ when measured at stage of grade III-IV encephalopathy in those who subsequently developed infection and there was a tendency for activity of all complement components to be lower in this group.

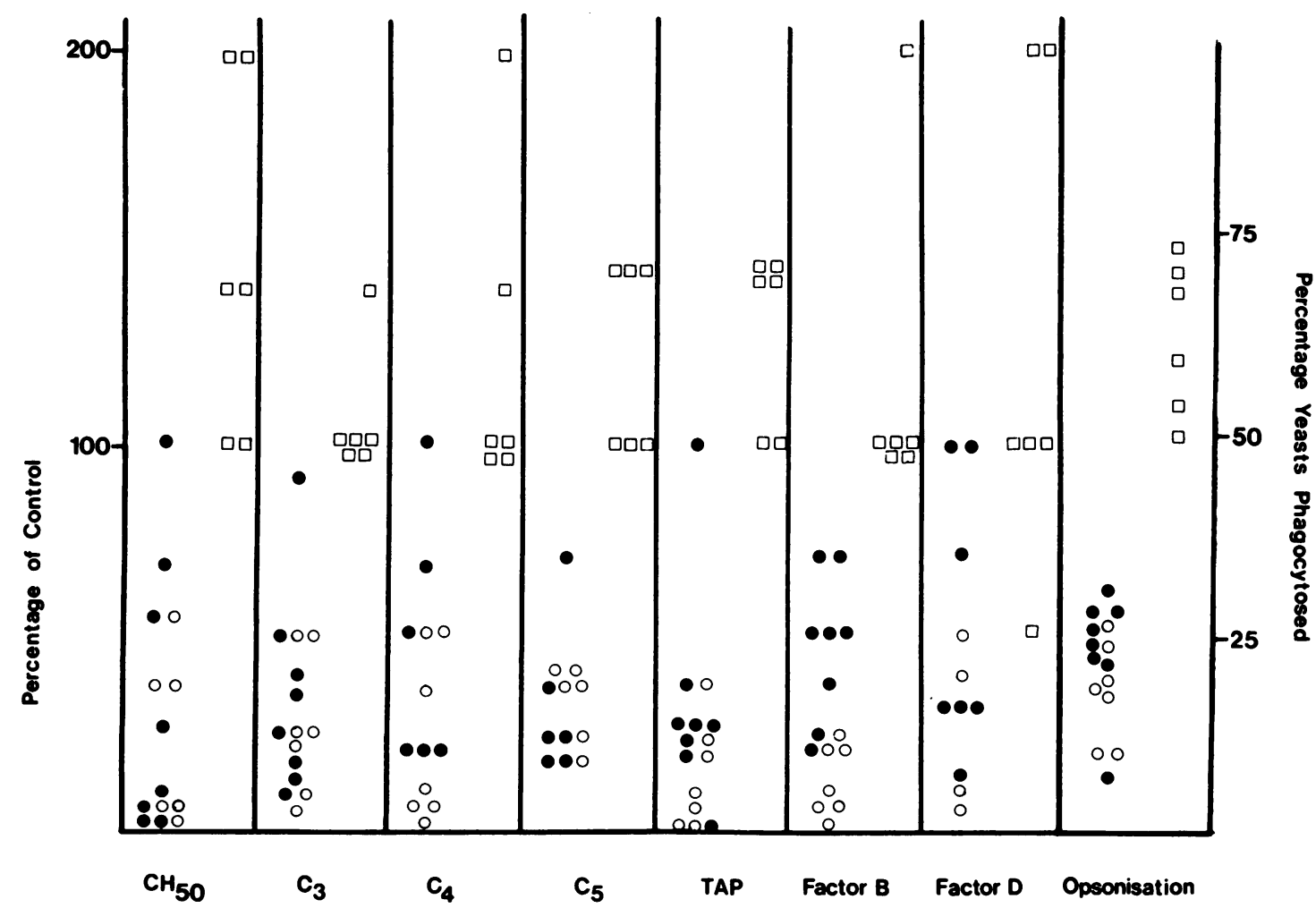

Fig. 1 Activity of complement components expressed as a percentage of control serum. CH50 = total haemolyte complement. TAP = total alternative pathway activity; opsonisation = percentage of yeasts phagocytosed (normal range $=32-72 \%$ ). Serum samples taken on admission at stage of grade III-IV encephalopathy. $\bigcirc$ Patients subsequently developing infection. $\bullet$ Patients not infected. $\square$ Recovered patients. 
Serial studies of opsonisation and complement were performed in 10 patients. The five who developed infection, and had a fatal outcome, showed a continuing reduction in opsonisation and complement despite clearance of encephalopathy (Fig. 2a). Bacteraemia occurred in these five patients at the time when opsonisation and complement components were deficient. In the two survivors opsonisation and complement became virtually normal within 14 days of admission and 10 days after clearance of encephalopathy (Fig. 2b). In the remaining three patients who failed to develop infection but nevertheless had a fatal outcome, opsonisation was in the low normal range, possibly as a result of plasma infusion (see below).

Opsonisation and complement remained normal (Fig. 1) in all six survivors whether studied six to eight weeks or more than 12 months after recovery.

\section{EFFECT OF PLASMA INFUSION}

One patient, whose serum was initially examined two days after plasma infusion given to correct clotting disturbances, had low normal opsonisation and complement activity. In five other patients opsonisation was measured before, and one day after, plasma infusion given to replace deficient clotting factors. The percentage of yeasts phagocytosed increased in all five (Fig. 3), though only reaching normal levels in two. Patients who developed infection had significantly $(p<0.05)$ greater intervals between plasma infusions (mean seven days) when compared with those who did not (mean 2.7 days).

Only one patient had a positive blood culture within four days of plasma infusion.

\section{Discussion}

The incidence of bacteraemia of $40 \%$ in this series of children with fulminant hepatic failure is higher than that reported in adults ${ }^{15} 16$ or in acute hospital admissions in children. ${ }^{17}$ Bacteraemia probably originated from urinary, gastrointestinal, or respiratory tracts or shunt sites and the organisms were predominantly body flora rather than resistant hospital flora. These factors, combined with evidence from other studies, ${ }^{16} 18$ imply that diminished host defences may be responsible for the

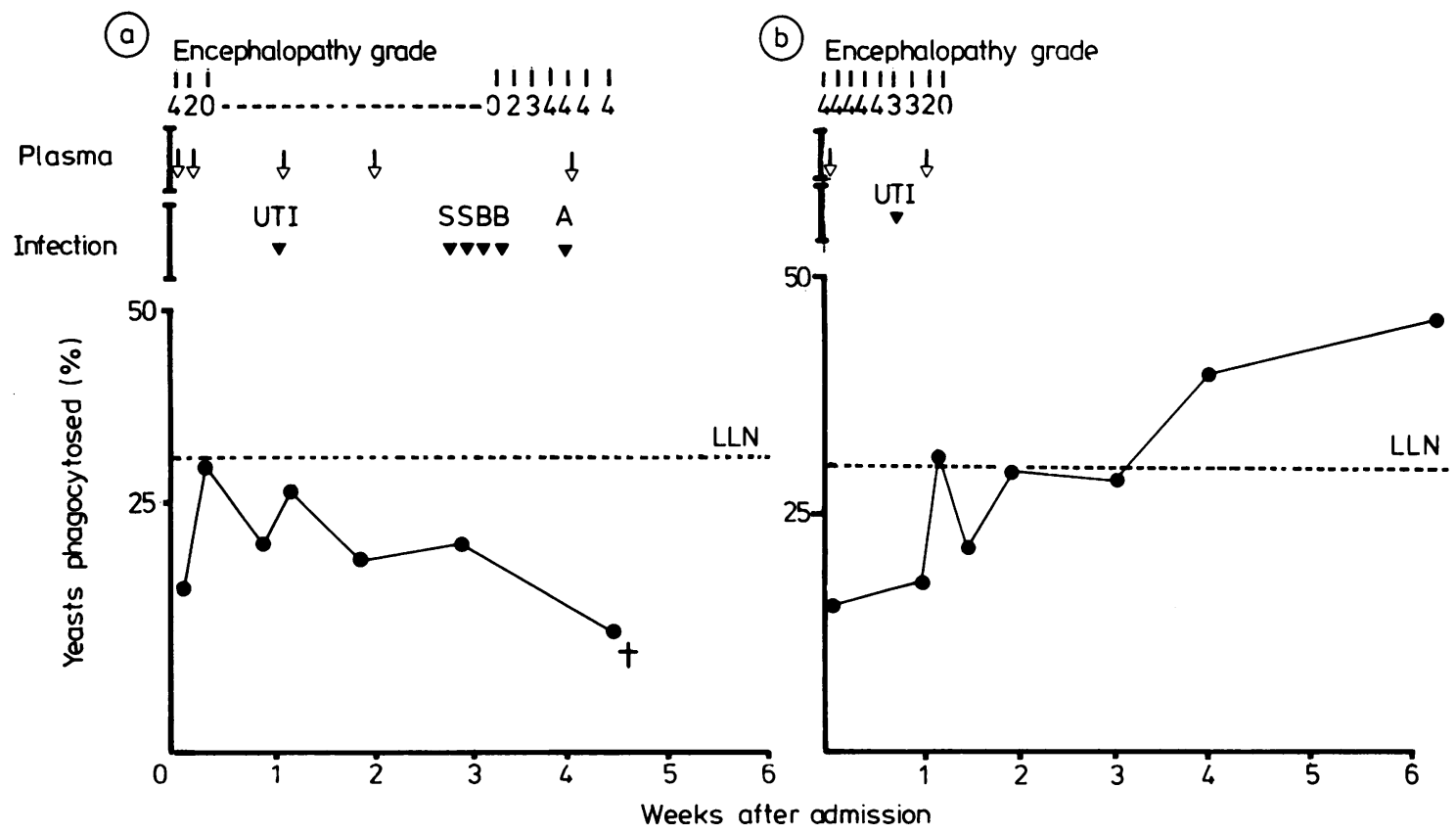

Fig. 2 Sequential determination of yeast opsonisation in two representative patients showing relationship between opsonisation, infection, plasma infusion, and grade of encephalopathy (0-4). (a) A fatal case (no. 6), who had a urinary tract infection (UTI), positive skin cultures (S) followed by isolation of an identical organism from blood (B); Gram negative organism seen in ascitic fluid (A) but not cultured. (b) A survivor, discharged from hospital on day 30 , who had a single urinary tract infection (UTI). 



Fig. 3 Effect of infusion of fresh frozen plasma (10-20 $\mathrm{ml} / \mathrm{kg}$ ) on the percentage of yeast phagocytosed. Serum samples taken pre (day 0) and post (day 1) plasma infusion. Dotted line indicates lower limit of normal range - that is, 2 $S D$ below control mean.

increased susceptibility to infection of patients with fulminant hepatic failure.

In considering possible mechanisms for the defect in host defence neither the profound metabolic and nutritional disturbances nor occurrence of encephalopathy nor treatment with haemodialysis appeared to be solely responsible for the development of infection, as they occurred with equal frequency in those patients who developed infection and those who did not.

None of the patients had deficiency of serum immunoglobulins and one patient only had neutropenia. Leucocyte function was not determined, but studies in adults with fulminant hepatic failure suggest that phagocytosis and killing by poly- morphonuclear leucocytes is normal. ${ }^{19}$ In contrast, functional deficiency in opsonisation and complement, to an extent previously associated with an increased incidence of infection, 36820 occurred in all patients at presentation and in all of five patients studied at the time of bacteraemia. In addition, opsonisation of yeasts and functional activity of factor B and C4 were significantly lower at presentation in those patients who subsequently developed infection than in those who did not.

These observations do not establish a causal relationship between complement deficiency and the high incidence of infection in fulminant hepatic failure, although increased susceptibility to pneumococcal septicaemia of animals after depletion of the alternative pathway of complement suggest that this relationship is possible. ${ }^{21}$ As complement is required for leucocyte chemotaxis, phagocytosis, and intracellular killing of bacteria, ${ }^{2}$ the widespread defects observed could have also contributed to the patients' apparent susceptibility to bacterial infection. Although complement deficiency could have resulted from complement activation and consumption in response to infection, this was unlikely, as defects occurred before and in the absence of infection, and levels of $\mathrm{C} 3$ activation products, C3d, are not increased in plasma of adults with fulminant hepatic failure (Vergani, unpublished results). It is more likely that the specific opsonisation and complement defects are a consequence of defective synthesis secondary to the severe hepatic necrosis. ${ }^{9}$

As bacteraemia may have contributed to the fatal outcome in four cases, early diagnosis and treatment of infection are imperative. Leucocytosis and pyrexia were unreliable indicators of bacteraemia in fulminant hepatic failure, as both may result from endotoxaemia and hepatic necrosis. ${ }^{22}{ }^{23}$ Although difficulties in diagnosis of bacteraemia exist, the use of prophylactic treatment with broad spectrum antibiotics can encourage overgrowth of the gastrointestinal tract by Candida, which apparently resulted in systemic candidiasis in two patients in the present series. Plasma infusion may be of therapeutic benefit, as plasma infusion in vivo resulted in a significant increase in opsonisation and complement measured in vitro in this and other studies ${ }^{20}$ and patients who developed infection had received less frequent plasma infusions than those who did not. The half life of the plasma factor responsible for yeast opsonisation is four to five days and, as bacteraemia was rare within four to five days of plasma infusion, it is tempting to speculate that such treatment might exert a protective effect against infection by improving opsonisation or complement function. Such infusions must, however, be used 
with care, as their high sodium load may produce hypernatraemia and fluid retention in patients with fulminant hepatic failure who have impaired sodium excretion as a result of functional renal failure. ${ }^{25}$

\section{References}

1 Psacharopoulos HT, Mowat AP, Davies M, Portman B, Silk DBA, Williams R. Fulminant hepatic failure in childhood. An analysis of 31 cases. Arch Dis Child 1980; 55: 252-8.

2 Johnston RB, Stroud RM. Complement and host defence against infection. J Pediatrics 1977; 90: 169-79.

3 Alper CA, Colten HR, Rosen FS, Rabson AR, Macnab G, Gear JSS. Homozygous deficiency of the third component of complement (C3) in a patient with repeated infection. Lancet 1972; 2: 1179-81.

4 Clark RA, Klebanoff SJ. Role of the classical and alternative pathways in chemotaxis and opsonisation; studies of human serum deficient in $\mathrm{C}_{4}$. J Immunol 1978; 120: 1102-8.

5 Stossel TP, Alper CA, Rosen FS. Opsonic activity in the newborn; role of properdin. Pediatrics 1973; 52: 134-7.

6 Strunk RC, Fenton LJ, Gaines JA. Alternative pathway of complement activation in full term and premature infants. Pediatr Res 1979; 13: 641-3.

7 Soothill JF, Harvey BAM. A defect in the alternative pathway of complement. Clin Exp Immunol 1977; 27: 30-3.

8 Turner MW, Mowbray JF, Harvey BAM, Brostoff J, Wells RS, Soothill JF. Defective yeast opsonisation and C2 deficiency in atopic patients. Clin Exp Immunol 1978; 34: 353-9.

9 Larcher VF, Wyke RJ, Mowat AP, Williams R. Mechanism of yeast opsonisation defect in children with fulminant hepatic failure. Clin Exp Immunol 1981; 46: 406-11.

10 Trey C, Davidson CS. The management of fulminant hepatic failure. In: Popper H, Schaffner P, ed. Progress in liver disease, vol 3. New York: Grune and Stratton, 1970: 282-98.

11 Saunders SJ, Hickman R, Macdonald R, Terblanche SJ. The treatment of acute liver failure. In: Popper $\mathrm{H}$, Schaffner P, eds. Progress in liver disese, vol 4. New York: Grune and Stratton, 1972: 333-44.
12 Levinsky RJ, Harvey BAM, Palleja S. A rapid objective method for measuring yeast opsonisation in serum. J Immunol Methods 1978; 24: 251-6.

13 Lachman PJ, Hobart MJ, Aston WP. Complement technology. In: Weir DM, ed. Handbook of experimental immunology. Oxford: Blackwell, 1973: 7-12.

14 Martin A, Lachmann PJ, Halbwachs L, Hobart MJ. Haemolytic diffusion plate assays for factors $B$ and $D$ of the alternative pathway of complement activation. Immunochemistry 1976; 13: 317-24.

15 Mummery RV, Bradley JM, Jefferies DJ. Microbiological monitoring of patients in fulminant hepatic failure with particular reference to extra corporeal porcine liver perfusion. Lancet 1971; 2: 60-4.

16 Wyke RJ, Gimson AES, Canalese J, Williams R. Bacteraemia in patients with fulminant hepatic failure. Liver (International) 1982; 2: 45-52.

17 Forfar JO. Demography, vital statistics and the pattern of disease in childhood. In: Forfar JO, Arneil GC, eds. Textbook of paediatrics. Churchill Livingstone, 1973: 26.

18 Wyke RJ, Rajkovic IA, Eddleston AWLF, Williams R. Defective opsonisation and complement deficiency in serum from patients with fulminant hepatic failure. Gut 1980; 21: 643-8.

19 Yousif-Kadaru AM, Wyke RJ, Rajkovic IA, Eddleston AWLF, Williams R. Serum factors affect movement of leucocytes in patients with fulminant hepatic failure. Clin Sci 1980; 58: 14p.

20 Soothill JF, Harvey BAM. Defective opsonisation; a common immunity deficiency. Arch Dis Child 1976; 27: 30-3.

21 Hosea SW, Brown EJ, Frank MM. The critical role of complement in experimental pneumococcal sepsis. $J$ Infect Dis 1980; 142: 903-9.

22 Wilkinson SP, Aroyo V, Gazzard BC, Moodie HE, Williams $R$. Relation of renal impairment and haemorrhagic diathesis to endotoxaemia in fulminant hepatic filure. Lancet 1974; 1: 521-4.

23 Gazzard BG, Portmann B, Murray Lyon IM, Williams $R$. Causes of death in fulminant hepatic failure and relationship to qualitative histological assessment of parenchymal liver damage. $Q J$ Med 1975; 176: 615-26.

24 Candy DCA, Larcher VF, Tripp JH, Harries JT, Harvey BAM, Soothill JF. Defective yeast opsonisation in children with chronic diarrhoea. Arch Dis Child 1980; 55: 189-93.

25 Wilkinson SP, Arroyo V, Moodie HE, Blendis LM, Williams R. Renal failure and site of abnormal renal retention of sodium in fulminant hepatic failure. Gut 1974; 15: 343-7. 